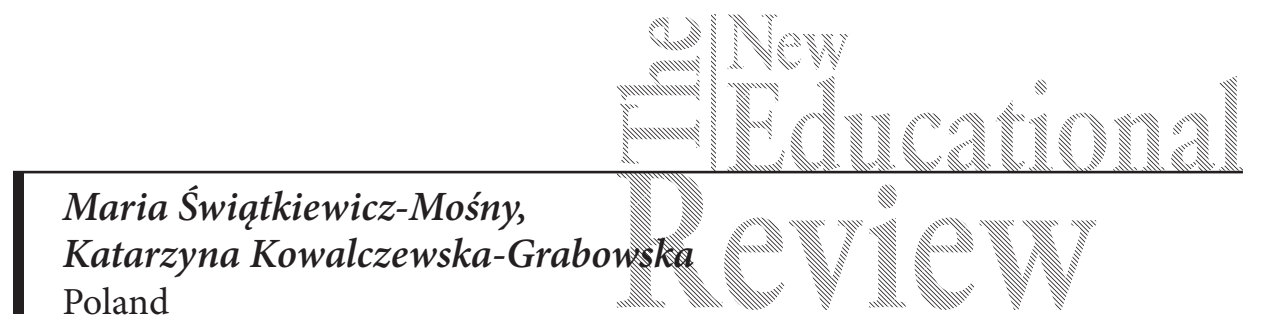

\title{
Youth and Cancer Prevention (with the Example of Cervical Cancer)
}

DOI: 10.15804/tner.2017.50.4.07

\begin{abstract}
The research results presented in this article originate from the research and educational project conducted from January to June 2017, titled Prevention of cervical carcinoma, or how it is done in Tychy. Analysis of knowledge sources and the views on HPV vaccines, which was funded with a grant by the Polish Cancer League Foundation. The research material allowed for formulating the guidelines for the educational and preventive treatment programs addressed to young people and their parents. Despite free vaccinations against the HPV virus from some local governments, the percentage of people covered by vaccinations is decreasing. What is needed in order to reverse the negative tendencies is a set of new, innovative solutions, addressed at the needs and expectations of the beneficiaries. Therefore, people should be educated on the risk of falling ill, while HPV vaccinations constitute an important element of primary prevention.
\end{abstract}

Keywords: youth, cancer prevention, cervical cancer

\section{Introduction}

Neoplasms are the second most common cause of deaths in Poland, right after cardiovascular diseases (GUS, 2016. Retrieved 15/08/2017, from: http://stat.gov. $\mathrm{pl} /$ ). The increase in incidence results, among others, from environmental reasons, but also from lifestyles. In certain neoplasms, preventive treatment proves effec- 
tive. However, preventive treatment requires specific, systematic activities aimed at future results. One of the strategies of prevention of cervical cancer is HPV vaccination. Its effectiveness depends on administration of the vaccine before sexual initiation. This means that very young girls undertake (together with their parents) activities which, in the unspecified future, will protect them from the disease.

In Poland, cervical cancer incidence amounts to ca. 11 people per 100,000 inhabitants (Didkowska, Wojciechowska, Zatoński, 2009), while on Malta, on Cyprus or in Finland - below 5 (WHO, 2013. Retrieved 22/10/2017, from: http:// apps.who.int/iris/bitstream/10665/78128/3/9789241505147_eng.pdf?ua=1). The WHO data shows that: "every year more than 270000 women die of cervical cancer, more than $85 \%$ of these deaths are in low and middle income countries" (WHO, 2013). The most exposed group is women over 30, mainly aged 45-59. The WHO data demonstrates that cervical cancer incidence and mortality are decreasing and are going to decrease, as a result of the conducted preventive activities, i.e., vaccinations and cytological screening. The data from the Polish Cancer Register (KRN) demonstrates that cervical cancer incidence has decreased in Poland by ca. $30 \%$ since 1980 , and the mortality rate - by ca. $45 \%$ (Cervical cancer. Retrieved 15/08/2017, from: http://onkologia.org.pl/nowotwory-szyjki-macicy-kobiet/).

The most frequent cause of the development of cervical cancer is infection with genital types of the human papillomavirus (HPV) (Kampikaho Turiho at al. 2014). There are 2 types of available vaccines against the most oncogenic types of the HPV: bivalent and four-valent (Kessler, 2017, p.176; Farouk, 2017, p.64). Their cost in Poland is not low (over PLN 1,000 for three full doses), so some self-governments make the decision to finance a vaccination program. One of such cities is Tychy', where a program of free HPV vaccinations was introduced in 2010. The direct inspiration for the research was the low percentage rate of the girls benefiting from the program - it does not exceed 60\% (apart from 2011, where the vaccinations covered $61.08 \%$ ), while in 2016 - it was a little over $30 \%^{2}$ of those entitled to vaccination.

HPV vaccinations, just like any other vaccinations, generate controversy. The anti-vaccination movements are not as active as in the case of MMR vaccines, but still certain activities aimed at discouragement are noticeable. The anti-vaccination discourse is still based on the famous article by A.J. Wakefield published in "The Lancet" in 1998, which challenged the effectiveness of vaccines against measles

\footnotetext{
Tychy is a city in the south of Poland.

2 Data from the Department of Social Issues and Health of the Tychy City Hall, Poland.
}

and rubella and associated them with autism. Although the article was withdrawn, and its author punished for unethical conducting of research and fraud, many people are still convinced that vaccines are harmful.

What is more, the issues associated with cervical cancer are also considered sensitive, because they are associated with intimate and sexual life. Research (Kamzol, at al., 2012) demonstrates that the knowledge of the incidence of cervical cancer is insufficient among women in Poland.

The article presented discusses the results of an extensive research program financed by the Polish Cancer League Foundation, associated with prevention of cervical cancer. The objective of the research was to present the way of thinking of prevention of cervical cancer, and to analyze the areas of knowledge and ignorance. The research conducted was of empirical and pedagogical character, which means that, apart from obtaining significant social data on a given community, the project participants had the opportunity to learn by acting and to become familiar with the latest, reliable knowledge of preventive treatment.

\section{Research Methodology}

The project methodology was based on the humanist paradigm. The questions asked were associated with the way of thinking of preventive treatments, as well as with the areas of knowledge and ignorance regarding cervical cancer:

- What is the motivation of girls and their parents to undertake preventive activities?

- What are the causes of refusal to take a vaccination?

- How are health and disease defined?

- What is the knowledge and ignorance regarding prevention of cervical cancer?

- What activities are undertaken by the inhabitants of Tychy in the scope of HPV vaccinations?

- Where do teenage inhabitants of Tychy and their parents get the knowledge on cervical cancer prevention?

The answers to the research questions were obtained on the basis of qualitative research: focus group interviews and moderated workshops.

The research was conducted from February to May 2017 in Tychy, among female pupils born in 2005 (12-year-olds who qualified for the program of free vaccinations) and their parents, during workshops. The research covered 69 female pupils from 4 Tychy schools and 10 parents (mothers). 
In order to obtain more information on the way of thinking about cervical cancer prevention in Tychy, there was also conducted a critical analysis of the local media. The text corpus included 9 press articles published in the local media during the program. The keywords used for searching for the articles were: "cervical cancer prevention", "HPV vaccinations", "vaccinations against cervical cancer" The search engines showed that the subject was not particularly interesting for the local media (from the beginning of the program, the Tychy media published only 9 texts about the free vaccinations). That is why the research was supplemented with an analysis of the promotional materials prepared by Outpatient Clinic No. 4, which executes the vaccination program in Tychy.

\section{Research Results}

\section{Sources of knowledge (press analysis)}

The informative function of the media in the scope of prevention may be applied in a functional manner. The media may provide space for the provision of information, development of knowledge, and management of ignorance. New media play a special role in the area of health and disease, as exemplified by Dr. Google (Robertson, Polonsky, McQuilken, 2014), who is becoming a general practitioner, always ready to "provide" information, "suggest" treatment, "console" with a story of recovery or "find" a support group.

The analyzed press materials from the local (Tychy) websites was very scarce - 9 articles were published over 7 years of the program. Every article presented a positive attitude towards vaccinations and encouraged the readers to use them. The journalists supported their arguments with statements by a professor, specialist in obstetrics, gynecology, gynecologic oncology, a consultant of the Faculty of Gynecology and Obstetrics in the Province Specialist Hospital in Tychy. Both the academic title and the affiliation legitimized the statements and gave the right to define the reality. The professor clearly encouraged people to get vaccinated, but also referred to systematic cytology. In his opinion, that was the main reason why the cervical cancer incidence and mortality are lower in such countries as the USA or Malta.

The analyzed articles demonstrate statistics from which it follows that in Tychy, the issue of cervical cancer incidence and mortality is not as serious as, e.g., in the nearby city of Chorzów. That statement is to reinforce the message of encouragement regarding vaccinations.

However, the key issue is the number of articles. The Tychy media do not enter the prevention campaign - and neither do they enter (or only enter sporadically) other prevention campaigns. The impact of the media in the modern world is visible in the saying that "if it is not on the Internet, it does not exist".

The source of knowledge of vaccinations may also be the website of the Outpatient Clinic that executes the program. In this case, it is a pop-up window with a poster with invitation to take a vaccine. However, it does not include any information to help make the decision, but only formal, organizational information. It is not particularly legible - the font does not seem big enough.

The catchphrase that is supposed to promote vaccinations: "adult decisions protect young lives" and the photograph presenting an adult woman and a teenage girl are not unequivocally addressed to the youth. Both women are dressed in white (which may symbolize health) and are smiling. The older (probably mother) is holding her hand on the younger one (probably daughter). The image of an adult and a young person is often used in preventive and pharmaceutical campaigns - it is to support the value of experience-based knowledge (symbolized by an adult) or to reinforce emotions by presenting strong relationships between a parent and a child (in this case: mother and daughter). It may also refer to the future (and probably that was the intention in this case) - today a girl - tomorrow an adult woman. The discrepancies between the left and right sides of the poster may make it less legible. The left side refers to the world of adults - mature people. The invitation on the right side of the poster is addressed to the girls born in 2005 .

Another issue which should be highlighted is the fact that the outpatient clinic conducting the program does not provide any information on the vaccinations. The message: free vaccinations against HPV may not be understandable for the persons who do not know that abbreviation and do not associate it with anything. The Outpatient Clinic website could be the place where reliable information on vaccinations is available.

The media, which constitute sources of information on the issues associated with health and diseases, do not become such sources in this case. The local media do not comment on the program of free vaccinations, do not become a platform of knowledge or exchange of experiences associated with cervical cancer prevention.

\section{Health and disease}

Health is one of the most important values in Poland (CBOS, 2013. Retrieved 29/08/2017, from: http://www.cbos.pl/SPISKOM.POL/2013/K_111_13.PDF). The way it is defined affects the way it is looked after; e.g., what activities are undertaken to preserve it. The workshop participants were asked to state their associations with health and disease. The female pupils presented their answers in graphical form, and their parents - in written form. 
The female pupils perceive health in holistic categories, taking into account the fundamental types of health, i.e., physical, mental and social health. The pupils questioned found it easiest to refer to physical health, and hardest - to the social aspects of health. Health was presented by such positive symbols as an apple (fruit, healthy food) or bicycle (healthy lifestyle) and such negative symbols as crossedout cigarettes and bottles of alcohol. Disease was defined by the female pupils as a sad condition associated with difficult emotions, as well as with its attributes, i.e., a syringe, a physician, an ambulance, etc.

The studied parents (mothers) also approach health from a holistic point of view. In their statements, they mentioned its value: "health is the most important and fundamental thing in life, and we realize that when we start being ill, seriously ill, when it turns out that health is of utmost importance... while work, money, everything else recedes into the background". Such an understanding is associated with treatment of health as an autotelic value (value in itself), not as an instrumental value (health as the tool for achieving other objectives).

Disease, understood as a pathological condition, appeared in the answers less frequently. It was understood as lack of health, but also as a situation that forces certain activities. It is a disease, a potential disease, or a disease of a family member, which provides motivation for undertaking preventive activities. Similarly, a case of disease results in the willingness to obtain knowledge in that scope. Health is to a smaller degree conducive to undertaking preventive activities and searching for information on a healthy lifestyle.

\section{Motivation - demotivation}

The research conducted by CBOS (2013) shows that the Polish demonstrate they are responsible for their own health. $74 \%$ of the respondents believed that everyone was responsible for their own health, and $20 \%$ - that the authorities were responsible. The responsibility for one's own health is particularly visible in demonstrating healthy behaviours associated with nutrition and lifestyle.

When describing their motivation for looking after their own health, the parents questioned highlighted two aspects: individual and social. The individual aspect was associated with the need to look after one's health in order to execute one's own plans, to achieve good psycho-physical fitness, to meet requirements, etc. The social aspect was mainly associated with family members and the respondents stated that care for them was conducive to undertaking pro-health activities. Attention was paid to motivation, resulting from diseases of family members, to undertake preventive treatment. Apart from many difficult emotions, a case of disease in family also results in more knowledge, including evidence-based medical knowledge, as well as experience-based knowledge. Personal experience provides strong motivation, including undertaking pro-health activities.

The mothers answered that the only demotivating factors were laziness and a lack of willpower. Both properties are assessed in a negative manner and the respondents were ashamed to indicate they made looking after health more difficult. What is surprising is that the disincentives listed were closely associated with personal traits, more internal than external factors, which are not subject to direct control, such as a lack of time, hard work, or financial trouble. This also demonstrates assumption of responsibility for one's health. Even if the preventive activities are not fully undertaken, there is the conviction that they should be undertaken and that one is responsible for one's health.

\section{Knowledge - ignorance}

Knowledge allows for managing risk and uncertainty and undertaking activities aimed at minimizing uncertainty and risk (Gross, McGoey, 2015). The pupils were asked to identify the most important risk factors of cervical cancer. They mainly indicated early sexual initiation and high sexual activity together with changing partners. This indicates the existing strong association between the uterus and sex life. Uterus is perceived as a sexual organ which, in turn, causes a certain degree of embarrassment and lack of openness in talking about that topic. The problem is becoming sensitive and a lot of gentleness and proper, intimate atmosphere need to be provided in order to address it. This generates areas of ignorance and establishes common knowledge which is not always consistent with the current medical knowledge.

The respondents disregarded such factors as the fifth and sixth decade of life and numerous pregnancies, but these factors are indicated in the literature as important risk factors for cervical cancer (Kulesza-Brończyk, Gąsiewska 2010 , p.73). The participation in the workshops allowed the teenagers to gain knowledge in that area.

Then, an attempt was made to test the current knowledge of the female pupils regarding prevention of cervical cancer. They were asked to mark the most important preventive activities.

The female pupils knew of primary preventive treatment and indicated one of the forms of secondary preventive treatment, i.e., a test for the presence of the oncogenic HPV. Cytological tests were not included as elements of preventive treatment against cervical treatment in the answers of the female pupils. It is an important piece of information which demonstrates that cytological tests are 
not only not commonly taken by women in Poland ${ }^{3}$, but also do not constitute a subject that is widely recognizable. The participation in the workshops allowed the teenagers to gain knowledge in that area.

\section{Social campaign - persuasion}

One of the tasks during the workshops was to prepare a social campaign in the scope of cervical cancer prevention. The objective was to get to know the arguments which might induce the girls and their parents to take vaccinations. The task for the female pupils was to prepare advertising posters connected with the above-mentioned subjects, addressed both to parents and their teenage peers.

All the educational posters prepared by the pupils concerned the future. Their contents do not include intimidation with a disease, but only a worry, a caution. At the same time, there was provided the very specific answer to what should be done to avoid the disease in the future (clear suggestion), e.g.: run to the outpatient clinic, get vaccinated.

The prepared posters demonstrated what should be done to prevent the disease, in a very direct manner (Fight for your daughter's health; Parents, get your children vaccinated). Some of the messages were very emotional and personal, e.g.: Save $m e$ ! The messages to peers included the issue of health that gives satisfaction, constitutes a positive value, but which should be looked after. In this case, it is not particularly difficult to look after your health, because it "doesn't hurt", "it's quick and cancer's done".

As for the above-mentioned message from Outpatient Clinic No. 4 regarding the prevention program - none of the messages included the elements which appeared in the actual Clinic poster. The pupils did not refer to experience-based knowledge (or any other knowledge), or to the authority of a mother (as a mature woman). The arguments in the posters are very straightforward, simple, pointing at specific activities and personalized (directed to particular persons).

\section{Vaccinations - pros and cons}

The issue of making the decision on having your child vaccinated was also discussed during the workshops with parents, who were asked about incentives or disincentives for issuing consent for having their child vaccinated against HPV.

3 The data published on 2 July 2017 by the Polish Health Fund demonstrates that only 19\% of the entitled women have used the free cytology program. Retrieved 02/07/2017, from: http:// nfz.gov.pl/dla-pacjenta/programy-profilaktyczne/dane-o-realizacji-programow/ .
The mothers participating in the workshops found it much easier to verbalize the reasons for making the decision on vaccination of their children. In particular, they mentioned the health aspects, but also the financial side (free vaccinations). The concerns associated with vaccination included, in particular, adverse effects. They listed the following reasons for not having their children vaccinated: laziness, "I wasn't vaccinated, so neither will my child", "people don't like being instructed", "because an HPV vaccine is not obligatory - if it was, then more people would get vaccinated".

However, the key issue seems to be a lack of knowledge of vaccinations (that such a vaccine exists at all) or of the program (that Tychy has a program of free HPV vaccinations). On multiple occasions, concerns were raised whether working people were able to manage the vaccination program ("people live in a hurry and don't have the power to handle and remember about vaccinations, especially when you have several doses"). Some mothers didn't know that Tychy had a program of free vaccinations, others knew but did not have the information on when or where one should go.

When the mothers were asked what could convince other mothers to make the decision on having their children vaccinated, they listed: "obtaining knowledge, talking to your child, the need to look after your child's health, future and health are more important than temporary discomfort, the message: if you want to protect your child from cancer - the message would be disturbing, but also very important". Information campaigns were suggested, which would both provide reliable medical knowledge of the vaccinations and precise and legible information on the program (how, when and where to have your daughter vaccinated).

One of the identified difficulties of the program is the problem associated with the school system. At the beginning of the program, it was addressed to the girls attending the $6^{\text {th }}$ grade of primary education. School could be an effective communication channel and space for dissemination of information. The school system reform caused 6-year-old children to attend school, and so now 12-year-old girls may be in different grades ( $6^{\text {th }}$ of primary school or $1^{\text {st }}$ of junior secondary school).

The qualitative analysis of the statements given by the female pupils allowed for getting to know their knowledge and opinions on health/disease as well as cervical cancer prevention. It also allowed for an understanding of individual motivations for demonstrating pro-health behaviors. 


\section{Discussion/conclusions}

It follows from the interviews with the parents of the female pupils born in 2005 that the motivation to undertake preventive treatment, including making the decision on vaccination, mainly results from personal convictions and experiences. The parents mainly mentioned the care for their family and the possibility to execute their life plans. All the mothers participating in the project supported the activity of free HPV vaccinations. The disincentives listed were laziness and a lack of willpower. Within the context of free vaccinations, it may be assumed that it is laziness that plays the key role in making the decision on having one's child vaccinated. The need to appear at an outpatient clinic with the child three times to get the respective doses, may prove a backbreaking task for many parents, not because of time limitations (the dates and times are adjusted to the parents and children), but mainly because of a lack of the willpower or consistence in following through with a decision made. The female students who prepared the advertising posters at the workshops associated with cervical cancer prevention, took into account the need to take vaccinations. The contents of the posters were very emotional (included such statements as: "Save me") with a simple instruction of what should be done (e.g., "run to the outpatient clinic"). At the same time, they emphasized the value of health.

\section{Acknowledgements}

The authors of the article would like to thank the Polish Cancer League Foundation for financing the research and educational project within the grant.

\section{References}

CBOS (2013). Wartości i Normy. Komunikat z badań (Values and standards. Survey report). BS/111/2013. Retrieved 29/08/2017, from: http://www.cbos.pl/SPISKOM. POL/2013/K_111_13.PDF.

Cervical cancer. Retrieved 15/08/2017, from: http://onkologia.org.pl/nowotwory-szyjki-macicy-kobiet/)

Data on the implementation of programs. Retrieved 02/07/2017, from: http://nfz.gov.pl/ dla-pacjenta/programy-profilaktyczne/dane-o-realizacji-programow/.

Didkowska, J., Wojciechowska, U., Zatoński, W., (2009). Prognozy zachorowalności i umieralności na nowotwory złośliwe w Polsce do 2025 roku (Predictions of cance incidence and mortality in Poland up to 2025), Centrum Onkologii - Instytut im. Marii
Skłodowskiej - Curie. Retrieved 16/08/2017, from: http://onkologia.org.pl/wp-content/ uploads/Prognozy_2025.pdf.

Farouk, M. (2017). Vaccines for Prevention of Cervical Cancer. Pakistan Journal of Medical Research, 56(2), p.64.

Gross, M., McGoey, L. (2015). Routledge international handbook of ignorance studies, Routledge, NewYOurk-London.

GUS (Central Statistical Office 2016). Retrieved 15/08/2017, from: http://stat.gov.pl/.

Kampikaho Turiho, A., Okello, E.S., Muhwezi W.M., Harvey, S., Byakika-Kibwika, P., Meya, D., Katahoire A.R. (2014). Effect of School-based Human Papillomavirus (HPV) Vaccination on Adolescent Girls' Knowledge and Acceptability of the HPV Vaccine in Ibanda District in Uganda. African Journal of Reproductive Health, 18(4), 45-53.

Kamzol, W., Jaglarz K., Tomaszewski, K. Puskulluoglu, M., Krzemieniecki, K. (2012) Assessment of knowledge about cervical cancer and its prevention among female students aged 17-26 years. European Journal of Obstetrics \& Gynaecology and Reproductive Biology, 166 (2), 196-203.

Kessler, T.A. (2017). Cervical cancer: prevention and early detection. Seminars in Oncology Nursing, 33(2), 172-183.

Kulesza-Brończyk, B., Gąsiewska, H., (2010). Profilaktyka chorób nowotworowych narzadu rodnego (Preventive treatment in neoplastic diseases of reproductive organs) In: Promocja zdrowia (Health Promotion). Tom II Promocja zdrowia w praktyce pielęgniarki i położnej. Ed. A. Andruszkiewicz, M. Banaszkiewicz. PZWL Warszawa, p. 73.

Macdonald, L., Deeks, S., Doyle, C. (2010). A Public Health Perspective on HPV Vaccination: Response to The HPV Vaccination Campaign: A Project of Moral Regulation in an Era of Biopolitics. The Canadian Journal of Sociology, 35(4), 627-631.

Robertson, N., Polonsky M., McQuilken, L. (2014). Are my symptoms serious Dr Google? A resource-based typology of value co-destruction in online self-diagnosis. Australasian Marketing Journal (AMJ), 22(3): 246.

WHO guidance note: comprehensive cervical cancer prevention and control: a healthier future for girls and women (2013). Retrieved 22/10/2017, from: http://apps.who.int/iris/ bitstream/10665/78128/3/9789241505147_eng.pdf?ua=1. 